\title{
Product market regulation and innovation efficiency*
}

\author{
Chiara Franco $^{\dagger}$ Fabio Pieri ${ }^{\ddagger}$ Francesco Venturini ${ }^{\S}$
}

\begin{abstract}
We study the role of upstream product market regulation (PMR) in innovation efficiency. By estimating a knowledge production function on OECD industries through a stochastic frontier analysis, we find that service regulation reduces $R \& D$ efficiency in the manufacturing sector. These results are robust to controlling for the institutional setting of the technology, the labour and the financial market, and to various forms of heterogeneity. The marginal impact of PMR is higher in less regulated economies indicating that large improvements in R\&D efficiency cannot be obtained at the earlier stages of deregulation. Potential efficiency gains for late reformers are however sizeable.
\end{abstract}

Keywords: R\&D, knowledge production, efficiency, product market regulation JEL classification: L5, L6, O3, O5.

*The authors wish to thank two anonymous referees for their useful remarks on a previous version of the paper. Comments by Jimmy Lopez, Xose-Luis Varela-Irimia, Michela Vecchi, Andrea Lasagni and seminar participants at 17th Spring Meeting of Young Economists (Mannheim), SAEe 2012 (Vigo), SIE 2012 (Matera), NIESR (London), Middlesex Business School, Universitat Rovira i Virgili, SIEPI 2014 (Naples), IO Workshop (Alberobello) and University of Trento are also greatly acknowledged. The usual disclaimer applies. Fabio Pieri acknowledges the financial support by the Spanish Ministry of Science and Innovation (project MINECO ECO2011-27619 co-financed with FEDER).

${ }^{\dagger}$ chiara.franco@unicatt.it. Department of International Economics, Institutions and Development, Catholic University of the Sacred Heart of Milan, Via Necchi 5, 20123, Milano, Italy

${ }_{\ddagger}^{\ddagger}$ fabio.pieri@uv.es. Departamento de Economia Aplicada, Universitat de Valencia, Avinguda dels Tarongers, s/n 46022, Valencia (Spain)

${ }^{\S}$ francesco.venturini@unipg.it. Department of Economics, Finance and Statistics, University of Perugia, Via Pascoli 20, 06123 Perugia (Italy) and NIESR, London (UK) 


\section{Introduction}

In the OECD area, differentials in productivity growth rates have been widening since the early 1990s (Nicoletti and Scarpetta, 2003). Most of this gap derives from service industries, where the regulatory framework is found to be severally detrimental for TFP growth, especially in Europe (Inklaar et al., 2008). This form of regulation generates sizeable negative effects on productivity even outside the tertiary sector, because of the intense intermediate transactions between producers and users of service inputs (Bourlès et al., 2013). One important channel through which service (upstream) regulation influences productivity in manufacturing (downstream) industries is by influencing the outcome of research Amable et al., 2009). Despite the relevant contribution provided by such pioneering studies, it still remains unexplained how imperfections in regulated intermediate input markets reverberate on manufacturing innovation. The object of the present paper is to identify one possible mechanism of transmission.

We postulate that upstream product market regulation (PMR) changes the ability of downstream industries (and firms) to efficiently manage $R \& D$ resources and carry out the complex set of innovation tasks. When intermediate input markets work imperfectly - due to administrative barriers, licensing, etc. - innovating firms suffer from difficulties in properly allocating factors of production, and cannot focus on their core activities due to the difficulty to outsource marginal tasks. Moreover, upstream regulation concurs to erecting entry barriers in downstream markets, changing the competitive pressure and incentives to innovate. Because of these factors, innovating firms may reach sub-optimal levels of R\&D efficiency, falling below the frontier of knowledge production.

We study the role of the regulatory setting of the upstream product markets by estimating a knowledge production function through a stochastic frontier analysis (SFA). In contrast to most existing works that exploit only one dimension of data variation (industry

or country), we use a fully comprehensive dataset covering fifteen manufacturing industries in ten OECD economies between 1990 and 2002. As widely documented in the literature, 
this was a period of intense pro-competition initiatives, rapid technological advancements but profoundly diverging patterns in productivity growth. In identifying the regulation impact on R\&D efficiency, we control for the institutional setting governing the functioning of the technology, the labour and the financial market, as well as several forms of heterogeneity such as, for instance, non-linearities in the effect of PMR along its distribution.

Our results provide robust evidence that upstream regulation remarkably reduces efficiency levels in manufacturing innovation. The marginal unit impact of PMR is larger in less regulated economies. It suggests that sizable improvements in R\&D efficiency cannot be expected at the initial stages of deregulation and that market liberalization takes time to produce widespread effects within the economy. We also find that the negative relationship between marginal impact and level of regulation strengthened during the 1990s when product market reforms were launched by most OECD economies. Overall, potential gains from deregulation are larger for those countries characterised by more restrictive administrative barriers to competition.

This paper makes an important contribution to three streams of literature. First, it contributes to the growing body of studies on the linkages between institutions and innovation (Nelson, 2008), by specifically exploring one dimension of the regulatory setting (upstream product market regulation) and identifying one channel of transmission (R\&D efficiency). Second, it broadens understanding of the growth effects of competition policies. Earlier studies have looked at the effect of regulation on investment (Alesina et al., 2005), occupational outcomes (Griffith et al., 2007, Fiori et al., 2012), workforce training (Bassanini and Brunello, 2011), export performance (Barone and Cingano, 2011), productivity growth and convergence to the frontier (Buccirossi et al., 2013, Bourlès et al., 2013). Third, relying upon recent developments in stochastic frontier analysis, we extend the literature seeking to identify the key factors underlying productivity growth (Kneller and Stevens, 2006, Henry et al., 2009) R\&D and patenting (Wang, 2007, Fu and Yang, 2009, Cullmann et al., 2012).

The remainder of the paper is the following. Section 2 surveys the literature on the 
nexus between product market regulation and innovation. Section 3 defines the analytical framework, discusses the econometric methodology and then presents data. Section 4 reports both descriptive statistics and the econometric evidence. Section 5 discusses the results and, finally, Section 6 concludes.

\section{Product market regulation and innovation}

\section{Theoretical background}

The latest Schumpeterian growth theories describe the relationship between product market regulation, competition and innovation as non-linear. This is the outcome of a race between two opposite forces (Aghion et al. 2013a). The first one is the pure competition effect of the old Schumpeterian tradition, which interprets ex-ante monopoly rents as a pre-requisite to innovate. The second one reflects the escaping-competition effect, which predicts that firms innovate to overcome competitors and earn ex-post monopoly rents. The former force prevails in 'unlevelled' markets where incumbents dominate, the latter in markets where firms are technologically contiguous and there is 'neck-to-neck' competition. In levelled markets, if firms do not collude, the fiercer the competition the higher the share of market profits going to the firm that innovates. On the contrary, in unlevelled markets, if competition increases, the incumbent's profitability reduces. On the aggregate, it emerges an inverted U-shaped relationship between competition and innovation which depends on the amount of sectors that are in the levelled state (composition effect). If the initial level of competition is low because of strict regulation, lowering administrative barriers should result in a faster rate of innovation. Conversely, when competition is initially high, there is little incentive for the laggard in an unlevelled state to innovate. One key prediction of this framework is that regulation discourages innovation the closer a firm to the frontier, but not far from it.

This general growth setting can be adapted to yield a large array of results. Amable et al. (2009) hypothesize that the $R \& D$ effort of the market leader raises the difficulty for the 
follower to innovate and move one step ahead along the product quality ladder. Under this condition, the relationship between competition and innovation may be U-shaped and the effect of competition (regulation) on innovation be harmful closer to (far from) the frontier. Bourlès et al. (2013) adapts the mainstream framework of Schumpeterian growth to allow for the knock-on effects of product market regulation, i.e. how regulation in upstream industries influences the economic performance of downstream firms and industries that use regulated intermediate factors such as service inputs. ${ }^{1}$ Because of barriers to entry, licensing, etc., downstream firms access to such inputs at higher prices or lower quality than in a market without frictions. These unfavourable conditions inhibit firms from outsourcing marginal tasks, properly allocating factor inputs and efficiently managing their core activities. In this model, imperfect competition in upstream sectors makes the search for intermediate input suppliers time-consuming and costly for new downstream firms. These costs provide market power to upstream suppliers, creating a gap between the price and the marginal cost of the intermediate input. This represents a barrier to entry in downstream markets reducing both the number of active producers and incentives of these firms to improve efficiency. When there is an increase in the competitive pressure of upstream markets, the bargaining power of these suppliers fall, as well as the expected costs for a downstream firm to find a supplier. Conversely, stronger competition in downstream (levelled) industries increases incentives to improve R\&D efficiency, widening the gap between pre- and post-innovation rents. Summing up, this model predicts that upstream regulation (competition) reduces (increases) incentives to efficiency and productivity improvements downstream.

\section{Empirical evidence}

The prediction that the relationship between competition and innovation follows an invertedU pattern has been supported by Aghion et al. (2005), whereas Aghion et al. (2009) document that a more intense competition enhances innovation in frontier firms, but discourages it in

\footnotetext{
${ }_{1}^{1}$ Bourlès et al. (2013, working paper version) builds upon the model originally developed by Lopez (2010) which consists in an extension of Aghion et al. (1997).
} 
non-frontier firms. Evidence departing from this pattern has recently been provided by Correa and Ornaghi (2014) who found that competition improves innovation and productivity performance. Griffith et al. (2010) assess the direct effects of own-industry regulation on innovation output. Examining the EU Single Market Programme's (SMP) reforms of the 1990s, these authors find that the fall in the administrative barriers to competition lowered firm profitability, therefore increasing incentives to carry out R\&D; as a result, firms innovated more and reaped larger productivity benefits. ${ }^{2}$

Attention has recently been paid to the empirical assessment of the knock-on effects exerted by product market regulation in service industries. Although these anti-competitive laws pertain the tertiary sector, their effects spread diffusely throughout the economy with the inter-industry (input-output) transactions of intermediate inputs (Conway et al., 2006). Imperfections in intermediate input markets are found to slow productivity growth, especially because of the deepening of globalization and ICT diffusion, since the 1990s Arnold et al. 2011, Bourlès et al., 2013). However, it remains less explored how the institutional setting of the intermediate input markets reverberates on R\&D of the manufacturing sector. Amable et al. (2009) show that upstream (service) regulation has a negative impact on patenting for countries far from the frontier, whilst this effect is positive for technology leaders. Consistently, Sanyal and Ghosh (2013) find that patenting in the field of electrical technology declined after the deregulation of the US electricity market during the 1990s. Blind (2012) provides evidence that PMR is unrelated to patenting when more dimensions of regulation policies are accounted for (competition legislation, price control, environmental laws). Conversely, using cross-sectional data at the firm level, Barbosa and Faria (2011) show that the probability to innovate is significantly lower in presence of a stricter regulation in upstream product markets, even when controlling for other institutional factors.

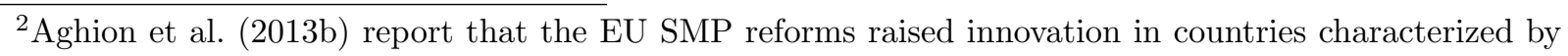
strong patent rights, but not elsewhere; this effect was more relevant in industries relying on patenting as a main tool of innovation.
} 


\section{Analytical framework}

\subsection{Econometric strategy}

We study the impact of upstream PMR on innovation efficiency of OECD manufacturing industries by applying a SFA to a knowledge production function (KPF). Innovation output $(I)$ is assumed to depend on research input $(R)$, international knowledge spillovers $(K)$, human capital $(H)$, and financial input $(F)$ :

$$
I_{i j, t}=A \cdot \mathbf{Z}_{i t}^{\theta}=A R_{i j, t}^{\gamma_{1}} K_{i j, t}^{\gamma_{2}} H_{i j, t}^{\gamma_{3}} F_{i j, t}^{\gamma_{4}}
$$

$i$ denotes industries, $j$ countries, $t$ time. $A$ is an exogenous productivity parameter of R\&D. $\mathbf{Z}$ is a factor aggregating function, $\theta$ a vector of factor elasticities. Eq. (1) is a variant of the knowledge production function devised by Ang (2011). We hypothesize that industries differ for the efficiency in factor usage:

$$
I_{i j, t}=A \cdot \mathbf{Z}_{i t}^{\theta} \cdot e^{\alpha_{i j}+\tau_{t}} \cdot e^{v_{i j, t}-u_{i j, t}}
$$

In natural logs, it is reworded as:

$$
\ln I_{i j, t}=\alpha+\theta \cdot \ln \mathbf{Z}_{i t}+\alpha_{i j}+\tau_{t}+v_{i j, t}-u_{i j, t} .
$$

Eq. (3) includes industry-country pair fixed effects in order to account for unobserved timeinvariant heterogeneity $\left(\alpha_{i j}\right)$, and year dummies to capture the impact of temporary common shocks $\left(\tau_{t}\right)$. To determine the knowledge production 'frontier', defined as the maximum attainable output by a given level of inputs, the stochastic component is modeled with a two-part error structure (Aigner et al., 1977; Meeusen and van den Broeck, 1977). $v_{i j, t}$ is a normally distributed disturbance capturing random departures from the predicted-by-themodel output (due to unobserved observation-specific random shocks, measurement errors, 
etc.). $u_{i j, t}$ is a half-normally distributed term capturing deviations from the frontier caused by a sub-optimal input usage, namely R\&D inefficiency (Wang, 2007, Fu and Yang, 2009). ${ }^{3}$

To assess how product market regulation (PMR) affects innovation efficiency, we adopt the one-step estimator devised by Wang and Schmidt (2002) and Schmidt (2011). It specifies the inefficiency term as a function of a set of covariates, and estimates their impact jointly with the determinants of the $\mathrm{KPF}^{4}$ Assuming

$$
v_{i j, t} \sim N\left(0, \sigma_{v}\right) \quad u_{i j, t} \sim N^{+}\left(0, \sigma_{u_{i j, t}}\right)
$$

the (in)efficiency equation can be expressed (in logs) as a function of an industry-specific measure of upstream product market regulation (to be described in detail below):

$$
\ln \sigma_{u_{i j, t}}^{2}=\rho_{0}+\rho_{1} \cdot P M R_{i j, t}+\rho^{\prime} \mathbf{W}_{t}+\eta_{i} \cdot t+\mu_{j} \cdot t
$$

$\mathbf{W}$ is a vector of institutional controls, available at the country level, used to avoid spurious correlation between PMR and innovation efficiency that may be induced by competition policies pursued in the other markets of the economy (technology, labour and finance). $\eta_{i}{ }^{\prime}$ s are industry-specific time trends capturing changes in structural characteristics of innovation (i.e. exogenous technical progress). $\mu_{j}$ 's denote country-specific time trends controlling for the evolution of the general institutional setting; if omitted, this may be confounded with the deregulation wave in the product markets started in the early 1990s. The coefficient $\rho_{1}$ is the key parameter of the analysis as identifying the impact of service regulation on the (in)efficiency of knowledge generating activities conducted by manufacturing industries.

\footnotetext{
${ }^{3}$ Unreported sensitivity results indicate that (in)efficiency estimates are robust to alternative distributions (i.e., the exponential function). The choice of the distribution is dictated only by computational tractability (Greene, 2008, p. 180).

${ }^{4}$ This procedure outperforms the two-step methodology mostly used in earlier works. The latter consists of first estimating inefficiency scores from a baseline function (such as for instance our KPF), and then regressing these values on a set of additional explanatory variables (product market regulation). The twostep procedure has been shown to yield biased estimates of the (in)efficiency parameters in presence of omitted variables in the first-step estimation.
} 
Some properties of the empirical model are worthy to point out. First, as discussed above, to get consistent estimates, the determinants of the KPF are estimated jointly with the inefficiency parameters $\left(\rho, \eta_{i}, \mu_{j}\right)$ by means of maximum likelihood. Second, the model is heteroskedastic in $u_{i j, t}$, as the variance of this term depends on (upstream) regulation measured at the industry-country level $(i$ and $j$ ), which is a necessary condition to obtain unbiased efficiency scores. ${ }^{5}$ Third, by allowing for individual heterogeneity $\left(\alpha_{i j}\right)$ and timevarying (in)efficiency $\left(u_{i j, t}\right)$, the model circumvents the distortion in the KPF parameters potentially related to the correlation between industry-country fixed effects and innovation inputs. If uncontrolled, this 'pure' heterogeneity would affect the overall residuals $\left(\epsilon_{i j, t}=\right.$ $v_{i j, t}-u_{i j, t}$ ), leading to an incorrect statement of technical (in)efficiency. The specification used in this paper is known as the 'true' fixed-effects model (Greene, 2005). ${ }^{6}$

\subsection{Data}

We use data for fifteen manufacturing industries observed between 1990 and 2002 in ten OECD countries. ${ }^{7}$

\subsubsection{Determinants of knowledge production}

We measure innovation output, $I_{i j, t}$, with the number of patents granted by the US Patent and Trademark Office (USPTO). Patent counts are distinguished by application year, industry and nationality of the assignee, i.e. the corporate or individual holding the intellectual

\footnotetext{
${ }^{5}$ See Kumbhakar and Lovell (2000, pp. 272-3) and Caudill and Ford (1993).

${ }^{6}$ Our work extends previous research in the field. For instance, Fu and Yang (2009) disentangle patenting at the economy-wide level into the effects of innovation capacity and efficiency, allowing for country fixedeffects within the (in)efficiency equation but no deterministic element within the frontier. Comparable works, using a similar specification without fixed effects but focused on output production efficiency, are Kneller and Stevens (2006) and Henry et al. (2009).

'Details are provided in the Web Appendix. Industry list: Food, beverage and tobacco; Chemicals; Pharmaceuticals; Rubber and plastics; Other non-metallic minerals; Basic metals; Fabricated metal products; Machinery; Office machinery; Electrical eq. and apparatus; Communication eq.; Medical and scientific instruments; Motor vehicles; Other transport eq.; Other manufacturing. Country list: Australia, Canada, Germany, France, Great Britain, Italy, Japan, The Netherlands, Sweden, US.
} 
property right over the patented innovation. ${ }^{8}$ Research input, $R_{i j, t}$, is measured by $\mathrm{R} \& \mathrm{D}$ capital. This variable is obtained from research expenses' data applying the perpetual inventory method and a geometrical depreciation rate of $15 \%$. As a proxy for the international knowledge spillovers, we follow Acharya and Keller (2009) and use the imports-weighted sum across industries and countries of foreign patent stocks. The idea is that technological knowledge is transmitted through trade and, in their innovation activities, recipient industries benefit from foreign technology in proportion to the intensity of their imports (see Franco et al., 2011 and Venturini, 2014 among others).

Human capital and financial input are defined as an exponential function of the labour share of high-skilled workers and the relative availability of financial funds, respectively ( $h s$ and $f d$ ). These variables are expressed in percentage terms and enter linearly the econometric specification, being our KPF estimated in logs. In essence, human capital is defined in a Mincherian way and, similarly to Mason et al. (2012), its level is benchmarked to the weight of low- and medium-skilled workers in the industry, $H=\exp \left(h s_{i j, t}\right)$. This variable should capture the contribution of total labour quality, and not only that of R\&D employees, to patenting (source: EU KLEMS 2008). Following the literature on the role of financial factors for R\&D (Maskus et al. 2012), we define $f d$ as an interaction between an industry measure of external finance dependence (benchmarked to the US average values of the 1980s) and a country-specific, time-varying indicator of financial development. Financial dependence is defined by the share of external funds on total capital expenditure (Von Furstenberg and Von Kalckreut, 2006). Financial development is alternatively approximated by the ratio to GDP of bank credit, private bond market capitalization and stock market capitalization (Beck

${ }^{8}$ Although patent data mainly account for the output of formal innovation, they present some important
advantages. Firstly, using applications at the USPTO, we work with a standardized measure of innovation
output that reduces measurement errors, as all innovators are subjected to the same IPR law. Secondly, we
cover the portion of innovations with higher quality as firms demand patent protection in the US -the world-
wide leading technology market- only for their most valuable ideas. As patent application data move closer
to the last date in the data set (2006), our series increasingly suffer from missing observations consisting of
patents filed in recent years that have not yet been granted (Hall et al., 2001). To circumvent such truncation
problem, we are forced to work with data until 2002 . However, we use information on patent applications
at the European Patent Office as robustness checks.


and Demirgü-Kunt, 2009). As pioneered by Rajan and Zingales (1998), a lower degree of financial development is particularly harmful for those industries mostly relying on external funds to finance innovation and other risky activities (Ang, 2011). $f d$ is designed to capture cross-sector heterogeneity in the impact of financial input, $F_{i j, t}=\exp \left(f d_{i j, t}\right)$.

\subsubsection{Determinants of innovation efficiency}

As a proxy for PMR, we use the index of the regulation impact from OECD Product Market Regulation dataset (Conway and Nicoletti, 2006). This indicator measures how anti-competitive legislation in the tertiary sector reverberates on downstream sectors using services as factor inputs. In essence, it quantifies anti-competitive regulation in nonmanufacturing industries (energy, transport and communications, retail and professional services) projecting its effect on downstream industries on the basis of the coefficients of service input requirements from Input-Output tables. Anti-competitive practices in service industries include: entry regulation, the extent of public ownership, vertical integration and the market structure.

To consistently identify the effect of upstream regulation on R\&D efficiency we control for a large set of confounding factors. We account for the institutional setting governing the functioning of the labor, the technology and the financial market. All these control variables are available at the country level, reinforcing our choice of including country- and industryspecific trends within the (in)efficiency term in order to collect unobserved time-varying heterogeneity.

The strand of studies on the relationship between labor market institutions and innovation is quite extensive. The impact of the regulatory framework does differ in accordance with the time/country coverage of the analyses, as well as with the institutional profile of the labor market under assessment (Menezes-Filho and Van Reenen, 2003). We consider the strictness of employment protection legislation, distinguishing between the regulation pertaining the dismissal of regular workers and legislation on temporary contracts (Venn, 
2009). Griffith and Macartney (2014) find that the former is associated with a higher level of patenting in firms engaged in incremental innovation, as it favours the accumulation of firm-specific human capital. By contrast, more stringent regulation on temporary workers is harmful for patenting in turbulent technology markets, where innovation is radical and firms need to rapidly adjust workforce skills to the new state of technological knowledge.

We also account for the possibility that the capacity to efficiently use R\&D resources is affected by the legal regime of intellectual property rights (IPR) protection. More specifically, we include a measure of IPR protection relative to the US levels Ginarte and Park, 1997). This country has been historically acknowledged for the strongest system to enforce innovation and, in our study, is the reference technology market where non-US innovating firms apply for. According to our view, firms that benefit from a domestic IPR framework closer to the US standards are likely to better manage R\&D, as knowing the administrative procedure to route patenting, enforce property rights, and license innovation. Samaniego (2013) provides evidence that IPR enforcement increases innovation spending in high-tech industries by influencing both the market entry and exit.

The potential impact of financial regulation is examined by a measure of the extent to which each country has been reforming the financial markets, such as for instance by reducing state control or barriers to intermediation operations (Abiad et al., 2008). Ang (2011) finds that financial liberalization is negatively related to patenting as it reduce savings, triggers financial instability and leads to a disproportionate expansion of the financial sector that crowds out high-tech industries.

\section{Results}

\subsection{Descriptive analysis}

Table 1 shows the average value at the country level of the variables entering the KPF and the institutional factors potentially explaining R\&D inefficiency. To increase data comparability, 
in this section we scale patent and $R \& D$ variables on the number of employees to account for the industry size.

Table 1: Determinants of KPF and R\&D efficiency: average values 1990-2002

\begin{tabular}{lccccc|ccccc}
\hline \hline & \multicolumn{4}{c}{ KPF } & \multicolumn{5}{c}{ (In)efficiency } \\
& $I$ & $R$ & $K$ & $H$ & $F$ & PMR & IPRP & EPL & EPL & FIN \\
& $($ p.e. $)$ & $($ p.e. $)$ & $($ p.e. $)$ & $(h s \%)$ & $(f d \%)$ & $(\%)$ & $($ rel. \%) & Reg. & Temp. & Ref. \\
AU & 2.3 & 16.3 & 1114.3 & 13.2 & 1.1 & 7.6 & 81.5 & 1.3 & 0.9 & 91.6 \\
CA & 2.6 & 25.4 & 407.1 & 18.7 & 1.3 & 7.0 & 87.2 & 1.3 & 0.3 & 97.1 \\
DE & 1.9 & 33.0 & 46.8 & 13.7 & 1.4 & 10.4 & 91.8 & 2.7 & 2.8 & 88.3 \\
FR & 2.4 & 72.5 & 98.8 & 14.8 & 1.1 & 10.2 & 87.8 & 2.4 & 3.6 & 94.1 \\
GB & 1.2 & 40.6 & 67.4 & 14.9 & 1.8 & 8.7 & 93.0 & 1.0 & 0.3 & 97.4 \\
IT & 0.7 & 26.1 & 50.4 & 4.6 & 0.9 & 15.9 & 90.7 & 1.8 & 4.7 & 79.1 \\
JP & 4.8 & 37.4 & 34.7 & 24.1 & 2.7 & 11.6 & 90.9 & 1.9 & 1.5 & 79.5 \\
NL & 4.0 & 57.8 & 386.5 & 8.3 & 1.3 & 6.9 & 93.5 & 3.1 & 2.1 & 94.9 \\
SE & 3.2 & 46.5 & 270.1 & 14.6 & 0.7 & 6.5 & 89.8 & 2.9 & 2.5 & 94.5 \\
US & 6.7 & 58.7 & 9.3 & 34.5 & 0.8 & 5.7 & 100.0 & 0.2 & 0.3 & 94.1 \\
& & & & & & & & & & \\
Mean & 3.0 & 41.4 & 248.5 & 16.1 & 1.3 & 9.1 & 90.6 & 1.8 & 1.9 & 91.1 \\
\hline \hline
\end{tabular}

${ }^{a} I=$ Patents; $R=\mathrm{R} \& \mathrm{D}$ stock; $K=$ International technology spillovers; $H=$ Human capital $(h s=$ labour share of high skilled reported); $F=$ Financial factor $(f d=$ relative financial development reported). p.e.= variables expressed per thousand employee. $P M R=$ upstream product market regulation. IPRP $=$ IPRs protection (relative to the US). $E P L$ Reg= employment protection legislation on regular contracts. $E P L T e m p=$ employment protection legislation on temporary contracts. FIN Ref=Financial reforms.

In terms of innovation output, US and Japan are the leading countries. Smaller European economies such as Sweden and the Netherlands rank relatively well, while the UK and Italy lag behind. Looking at the innovation effort, as measured by R\&D stock, France is ahead, ranking much better than for patents per employee. Australia and Canada are characterized by a relatively low value of research capital per worker. As expected, smaller countries display higher values of the technology spillover variable. The United States stand out for the labour share of high-skilled workers, whereas Japan for the extent of the financial input.

Turning to the determinants of R\&D inefficiency, the largest EU countries (Italy, France, and Germany) and Japan denote the heaviest anti-competitive regulation in services; conversely, the US and Sweden fall in the upper tail of the distribution. The UK exhibits levels of IPRs protection relatively close to the US and, on the financial ground, it was the country that more intensively liberalised the market between 1990 and 2002. As for employment protection, the Netherlands emerge for the most restrictive discipline on regular contracts, Italy on temporary contracts. 
Overall, our descriptive statistics indicate that, in terms of input/output combination, there is a wide range of possibilities in conducting innovation, as those countries that lead for patenting not necessarily invested more in research inputs (and viceversa). This may be due to a different degree of R\&D efficiency.

\subsection{Estimation results}

Table 2 shows the baseline estimates for Eqs. (3) and (5). At first, we look at how R\&D stock, taken alone, contributes to patenting (cols. 1-2). Then, we consider all inputs of the knowledge production function (cols. 3a-3c). In these regressions, PMR is treated as the sole determinant of innovation efficiency, whilst the last estimates of the table account for the full set of institutional factors (cols. 4a-4c). As described above, financial input is defined as industry financial dependence alternatively multiplied by the value of bank credit, private bond market capitalisation and stock market capitalisation over GDP.

In cols. (1)-(2) the cumulative value of $\mathrm{R} \& \mathrm{D}$ has a positive and significant effect on patenting (around 0.25-0.27). The positive coefficient for $\rho_{1}$ implies that PMR raises the variance of the inefficiency distribution (0.19) or, put it in other words, that more stringent regulation in service industries is associated with a lower efficiency in the knowledge generating activities conducted by manufacturing (downstream) industries. ${ }^{9}$

In regressions (3a) through (3c), we estimate the extended knowledge frontier, finding a slightly smaller elasticity for R\&D capital. International technology spillovers are another crucial factor for the creation of new technological knowledge. As documented in the literature (Bottazzi and Peri, 2007), the impact of this variable exceeds returns to internal R\&D. Also, we detect a positive effect of financial input on patenting, which is statistically more robust when financial development is measured by the ratio to GDP of private bond and stock market capitalisation, in line with Maskus et al. (2012) and Ang (2011). Conversely, there is no evidence that the labour quality exerts an effect on innovation output at the

\footnotetext{
${ }^{9}$ Notice that parameters of the inefficiency equation cannot be interpreted as marginal effects (Liu and Myers, 2009). This issue will be addressed in Section 5 .
} 


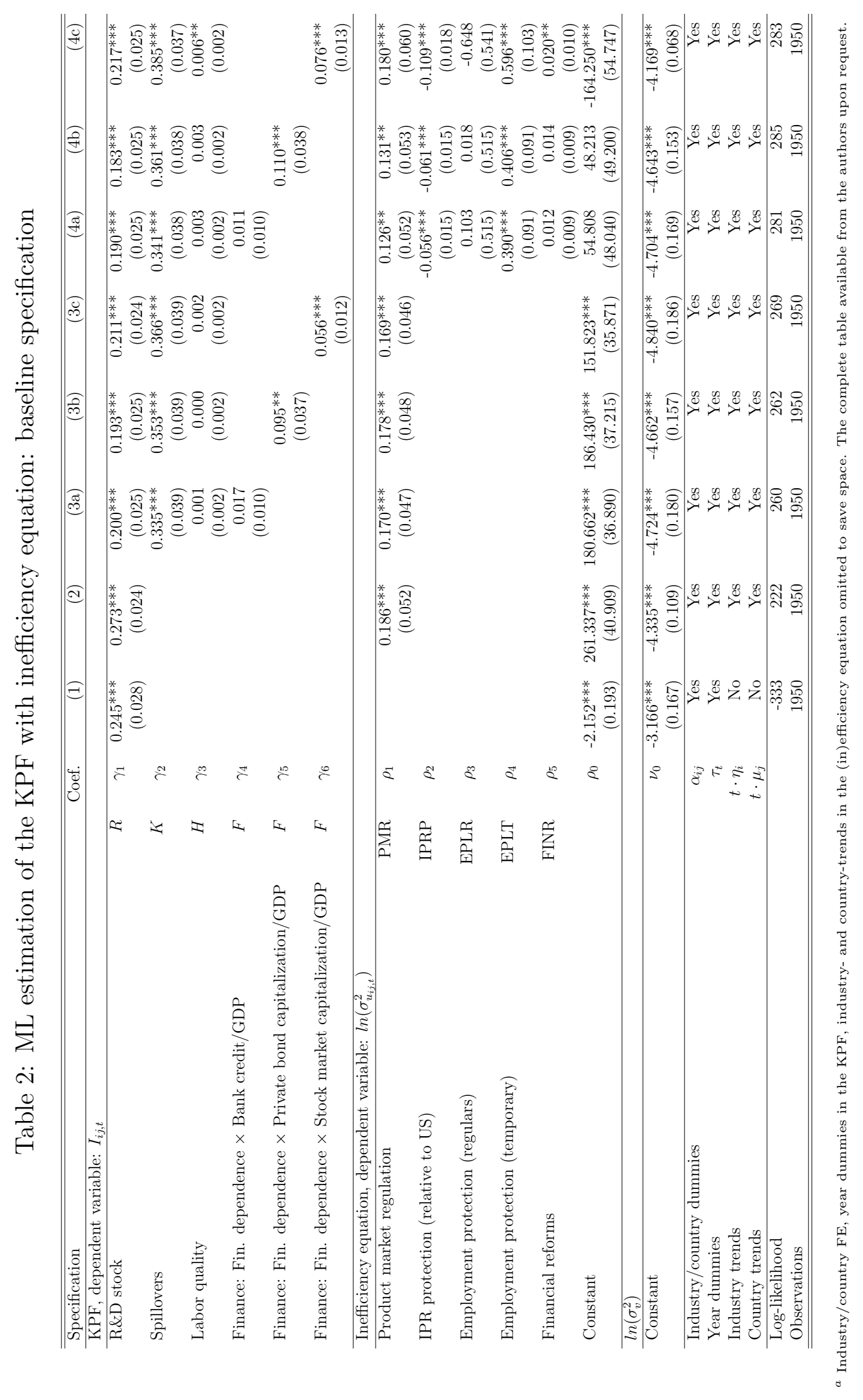


industry level (see Venturini, 2012 for comparable evidence). It would suggest that only the human capital of researchers - that is accounted for by the wages paid to these workers and hence is included in R\&D statistics - is significant to patent. In this second group of regressions, the effect of PMR on the variance of the inefficiency distribution is smaller than in col. (2).

In order to assess the robustness of the regulation impact, we introduce institutional controls and find confirmation of our previous results (cols. 4a-4c): the coefficient of PMR is positive and significant, ranging from 0.126 to 0.180 . Looking at the control variables, it should first be noted that IPRs protection has a negative coefficient; it means that a well defined set of rules on the technology market helps firms organize at best the entire array of research tasks (access to finance, R\&D operation, innovation licensing, etc.). ${ }^{10}$ Conversely, employment protection legislation denotes a strongly heterogeneous impact. Indeed, whereas the legal discipline on regular contracts does not have a robust effect, protection for temporary workers remarkably enhances $R \& D$ inefficiency. The latter is fully consistent with the effect found by Griffith and Macartney (2014) on radical innovation of multinational enterprises. Liberalizing employment protection for temporary contracts, while leaving in place stringent regulations on permanent contracts, may have adverse effects on the accumulation of firm specific human capital, as firms substitute temporary for regular workers and temporary workers are less likely to participate in job-related training Martin and Scarpetta, 2012). Though, below, we show that these findings hide large cross-country disparities. Furthermore, there is some indication that R\&D efficiency is lower in those economies where financial liberalisation is more pronounced. This finding is in accordance with Ang (2011) who detects a negative impact of financial reform on patenting. From this perspective, our work identifies one possible channel through which this effect transits, i.e. R\&D efficiency. There are some reasons that can motivate this finding. First, changes in the sources (and the

\footnotetext{
${ }^{10}$ The relationship between IPR stringency and innovation remains a debated issue (Boldrin and Levine, 2013). Furthermore, the strength of patent protection may interplay with the policies pursued in other markets, for instance enhancing the positive impact of product market liberalization on R\&D and patenting (Aghion et al. 2013b).
} 
extent) of funding may force firms to re-organize R\&D activities, and this implies sustaining large adjustment costs. Second, the higher financial instability induced by financial reforms in the short run may increase inefficiencies in firm operations. Third, knowledge generating activities may be crowded out by the disproportionate expansion of the financial sector resulting from liberalization, as this distorts the allocation of highly skilled workers away from the research sector. Putting this finding in perspective with estimates of the KPF, our evidence suggests that a large availability of financial funds is beneficial to innovation output as providing resources to carry out research activities; though, an excessive (or a too fast) deregulation of the financial market is harmful as, in the short and medium run, it may generate inefficiencies in how these activities are conducted. These results are widely confirmed by robustness checks below. ${ }^{11}$

Before proceeding with the sensitivity analysis, we assess the validity of the model's assumptions by conducting generalized likelihood-ratio tests on parameters (Table 3). As a first check, we examine whether inefficiency is truly contained in the data and, to this aim, we test the baseline knowledge production 'frontier' (col. 1, Table 2) against the 'average' knowledge production function (the latter would imply $u_{i j, t}=0$ for all $i j, t$.) The LR test for the hypothesis that $\sigma_{u}=0$ indicates that the variance of the inefficiency term statistically differs from $0\left(\chi^{2}=20.6\right)$, confirming the validity of our assumptions. Moreover, we evaluate whether the set of both industry/countries fixed effects and time dummies are significant in the $\operatorname{KPF}\left(\alpha_{i j}=0\right.$ or $\left.\tau_{t}=0\right)$, finding confirmation for both hypotheses. Finally, we assess the significance of the inefficiency equation's parameters using regression (4a) as a benchmark, given that it provides a more conservative value for the PMR parameter. When covariates are considered altogether, or PMR is taken alone, the null hypothesis is always refuted, proving that $\mathrm{R} \& \mathrm{D}$ (in)efficiency depends on institutional factors and the model is heteroskedastic. $^{12}$

\footnotetext{
${ }^{11}$ We thank an anonymous referee for emphasizing this point.

${ }^{12}$ Unreported LR tests indicate that industry- and country-specific time trends included into the inefficiency term are always different from zero. It confirms that, to consistently estimate the effect of upstream regulation, it is crucial to control for the deterministic evolution of this variable over time. In accordance
} 
Table 3: Generalized LR tests on parameters of the frontier model

\begin{tabular}{llccc}
\hline \hline Null Hypothesis & Specification & Conditions & $\chi^{2}$ statistics & Critical values (5\%) \\
\hline No inefficiency & 1 & $\sigma_{u}=0$ & 20.56 & $2.71^{a}$ \\
No Industry/country dummies & 1 & $\alpha_{i j}=0$ & 5318.54 & 178.48 \\
No Year dummies & 1 & $\tau_{t}=0$ & 704.95 & 21.02 \\
No heteroskedasticity in $u_{i j, t}=0$ & $(4 \mathrm{a})$ & $\rho_{k \neq 0}=0$ & 1091.88 & 42.55 \\
No PMR effect upon $u_{i j, t}=0$ & $(4 \mathrm{a})$ & $\rho_{1}=0$ & 10.74 & 3.84 \\
\hline \hline
\end{tabular}

${ }^{a}$ This test is at the boundary of parameter space $\left(\sigma_{u}\right)$; the critical value comes from Kodde and Palm (1986).

\subsection{Sensitivity analysis}

In this section, we carry out a battery of robustness checks to verify whether the regulation impact changes when accounting for a different set of inputs within the KPF (Table 4), for parameter heterogeneity among country groups (Table 5) and possible endogeneity, omitted variables and measurement errors in estimating the R\&D inefficiency (Table 6).

In Table 4, we first use a proxy for financial input based on the degree of asset tangibility, in place of external finance dependence. The firm's need for external funds may be indeed ultimately determined by capital structure and, hence, asset tangibility could better capture industry variation in the use of financial input (Maskus et al., 2012). ${ }^{13}$ In col. (1), we do not observe any change in the effect of financial input whilst, in absolute terms, the impact of the inefficiency determinants is larger. Then, we introduce a time-varying control for the industrial structure, defined as the sector share on total employment, to assess whether the expanding industries patent more because of larger technological or commercial opportunities. This expectation is confirmed by regression (2) in which we also find a positive and statistically significant effect for labour quality. In col. (3), we account for heterogeneity in trade specialization. The propensity to patent in the US might indeed reflect the export intensity of a country towards this market. ${ }^{14}$ However, when we include the US share of with Fiori et al. (2012), when time trends are omitted PMR turns out to be insignificant. Our model is sufficiently articulated and introducing country-year fixed effects, to control for country-specific economic shocks that may induce product market reforms, does not improve estimates due to convergence problems.

${ }^{13}$ Asset tangibility is given by the average share of structure, transport and non-ICT equipment on total capital expenditure, observed on the US industries in the 1980s. Notice that the high correlation between the measures of financial input based on external finance dependence and asset tangibility inhibits the inclusion of both variables within the same specification.

${ }^{14}$ For the US, we consider the cross-country average value of import shares. 
industry exports, this variable has a negative impact on patenting, albeit not economically relevant. This finding may be explained with the use of country-industry fixed effects, time dummies and the trade specialisation variable within the same specification. In the last two columns of Table 4 we respectively use R\&D expenses (in real terms) as a measure of research input (col. 4), and weight patent indicators with forward citations to account for the quality of innovation (col. 5). In these regressions the impact of R\&D input is substantially smaller whilst the spillover effect varies with the specification used; conversely, the parameter of PMR is broadly and stably larger than in our benchmark specification (col. 4a, Table 2).

Table 5 examines the results' sensitivity to the composition of country sample. In such estimates, we use the full set of financial development indicators to better account for crosscountry disparities in the functioning of the financial market. In cols. (1a)-(1c), we exclude the US to rule out the possible home bias associated with the usage of USPTO data to measure innovation output. Estimates do not change remarkably but, as expected, the impact of PMR is stronger.

As discussed above (Nicoletti and Scarpetta, 2003; Inklaar et al., 2008), there is large consensus that the EU has been struggling in terms of productivity performance because of an institutional architecture of the markets less conducive to economic growth. We assess this hypothesis by re-estimating the model considering the EU member states only (cols. 2a-2c). Interestingly, the impact of product market regulation on R\&D efficiency does not systematically differ from the rest of the sample. Rather, in Europe, research efficiency has been depressed by the legal discipline of regular labour contracts (whilst it is unrelated to the protection for temporary workers). These results conform to the analysis on the drivers of the productivity catch-up carried out by Bassanini et al. (2009) on OECD countries. ${ }^{15}$ Another valuable finding is that the detrimental effect of financial deregulation on innovation efficiency is much stronger than resulting from our previous estimates.

\footnotetext{
${ }^{15}$ We also inspect whether there is heterogeneity in the impact of PMR according to the technological base of production. There is evidence that high-tech sectors are less influenced by PMR; however, this finding is quite sensitive to the grouping criterion.
} 


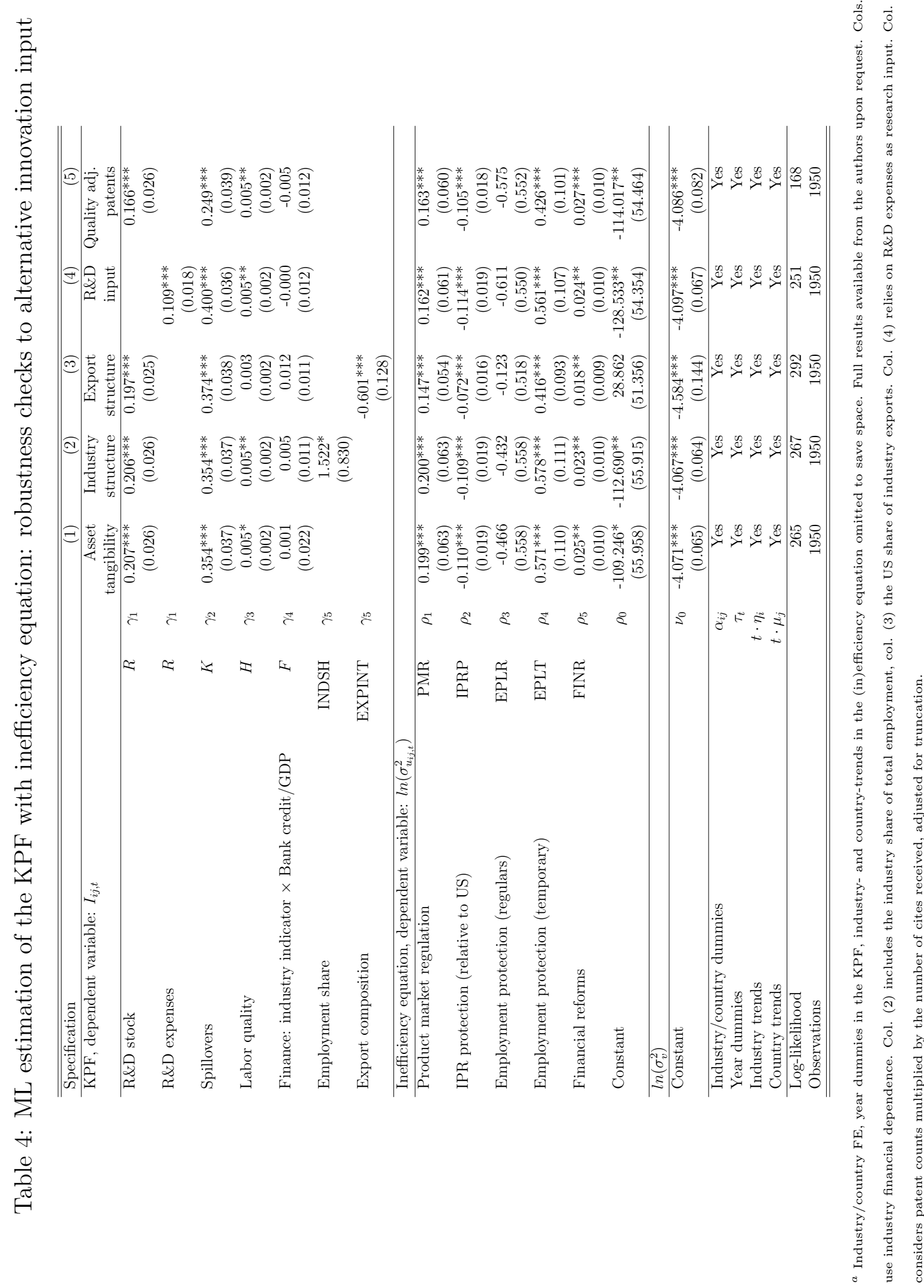




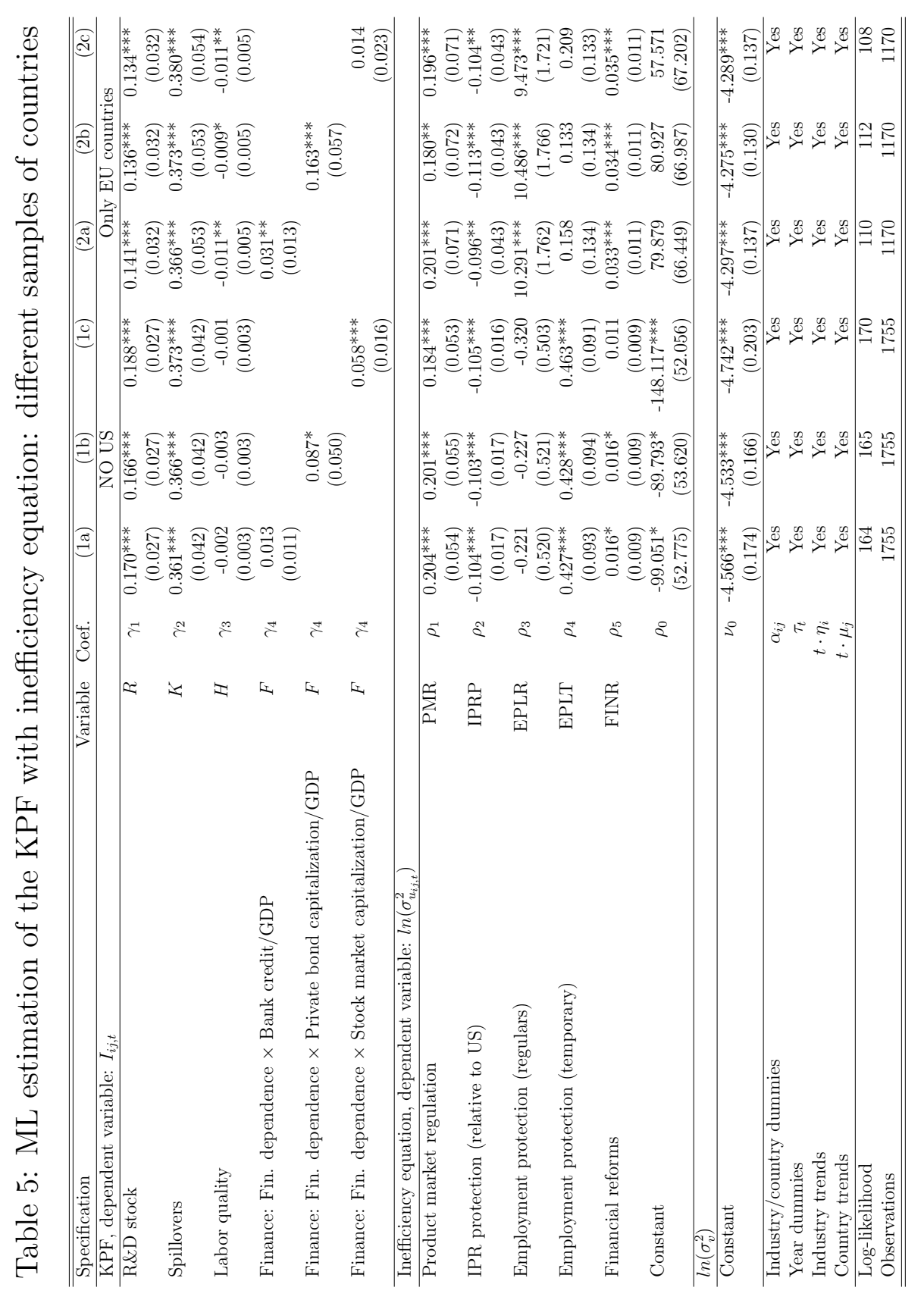

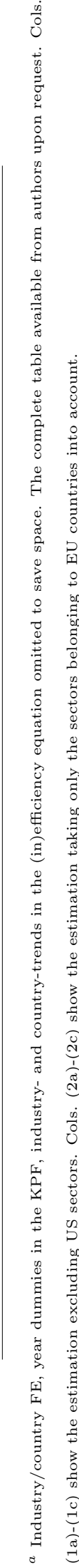


In Table 6, we address endogeneity, omitted variables and measurement errors problems in the estimation of R\&D inefficiency. Endogeneity may derive from simultaneity feedbacks from R\&D performance to the stringency of upstream regulation. In essence, the most successful innovators may grow in size and decide to internalize service tasks to escape unfavourable conditions imposed by service providers. This would lower interindustry transactions of intermediate inputs reducing the value of the regulation indicator. In this case, causality would run from innovation to upstream regulation and the estimated effect of PMR would be upward biased. To mitigate this risk, we estimate our model by using one- and three-year lags of the regulation indicator (cols. 1a-1b). In such regressions, the parameter of PMR is still significant, fluctuating around the value of our benchmark specification (0.126). Similarly, in col. (1c) we estimate the KPF using the one-year lagged values of innovation inputs, obtaining a larger coefficient for PMR. More generally, firms' usage of intermediate inputs may respond to, or anticipate, changes in service regulation irrespective of the outcome of R\&D activities. To overcome this reverse-causality problem, it is a standard practice to adopt the structure of intermediate input transactions of a benchmark country, assuming that it approximates (exogenous) industry technological differences and that these are common across countries (Barone and Cingano, 2011). To this aim, we build an alternative indicator of upstream regulation using the intermediate transaction coefficients of the US as weights (taken from 1990 input-output tables) and exclude this country from the analysis. This practice may however fail when industry technologies are heterogeneous across countries and idiosyncratic shocks to the US economy are larger than those affecting other countries (Ciccone and Papaioannou, 2010). The former would consist in a measurement error leading to upward biased coefficients for those countries with a (relatively) technologically backward structure of the economy (amplification bias). The latter would result in a classical measurement error attenuating the PMR parameter towards zero (attenuation bias). Results in col. (1d) seem in accordance with the latter explanation as the coefficient of upstream regulation is no longer statistically significant. Overall, notwithstanding the relatively long time lag 
between the design and the implementation of the changes in competition legislation and our attempts to minimize reverse-causality problems, we cannot exclude that some residual endogeneity may affect our findings.

To further refine the assessment of the institutional factors influencing R\&D efficiency, in col. (2) we include country-wide rates of union density. ${ }^{16}$ Trade unions may act as a hindrance to innovation when this leads to firm re-structuring or worker dismissal, determining an inefficient factor allocation (Menezes-Filho and Van Reenen, 2003, Venturini, 2012). This expectation is confirmed by regression (2) in which, though, the coefficient of other institutional factors remains unaffected.

Finally, we evaluate our results to the use of alternative patent data. Specifically, we adopt patent applications at the European Patent Office (source: OECD EPO patent database) and with such data we are able to extend the analysis up to 2007 (cols. 3a and $3 \mathrm{~b}$ ). EPO patents yield quite different results (col. 3a) both for the determinants of the KPF and the R\&D efficiency. In the frontier, we find a smaller effect for R\&D capital and larger international spillovers, whereas labour quality is more statistically related to patenting; in contrast with most previous studies, financial input is found to reduce innovation output. More importantly, R\&D efficiency is estimated less precisely and, now, only EPL on temporary contracts shows an impact consistent with our previous estimates. The coefficient of PMR is still positive but not significant. These findings may be explained with a lower quality content of EPO patents which refer to the demands for patent protection and these may not be accepted at the end of the examination because of the lack of novelty and originality (contrarily USPTO application data that refer to granted patents). In general, estimates based on EPO seem to suffer a larger home bias. ${ }^{17}$

\footnotetext{
${ }^{16}$ Union density is defined as the percentage ratio between trade union members and the total number of wage and salary earners.

${ }^{17}$ This is also witnessed by running regressions (3a)-(3b) separately for the EU and non-EU countries; for the latter, as our modelling of R\&D efficiency shows a very low explanatory power.
} 


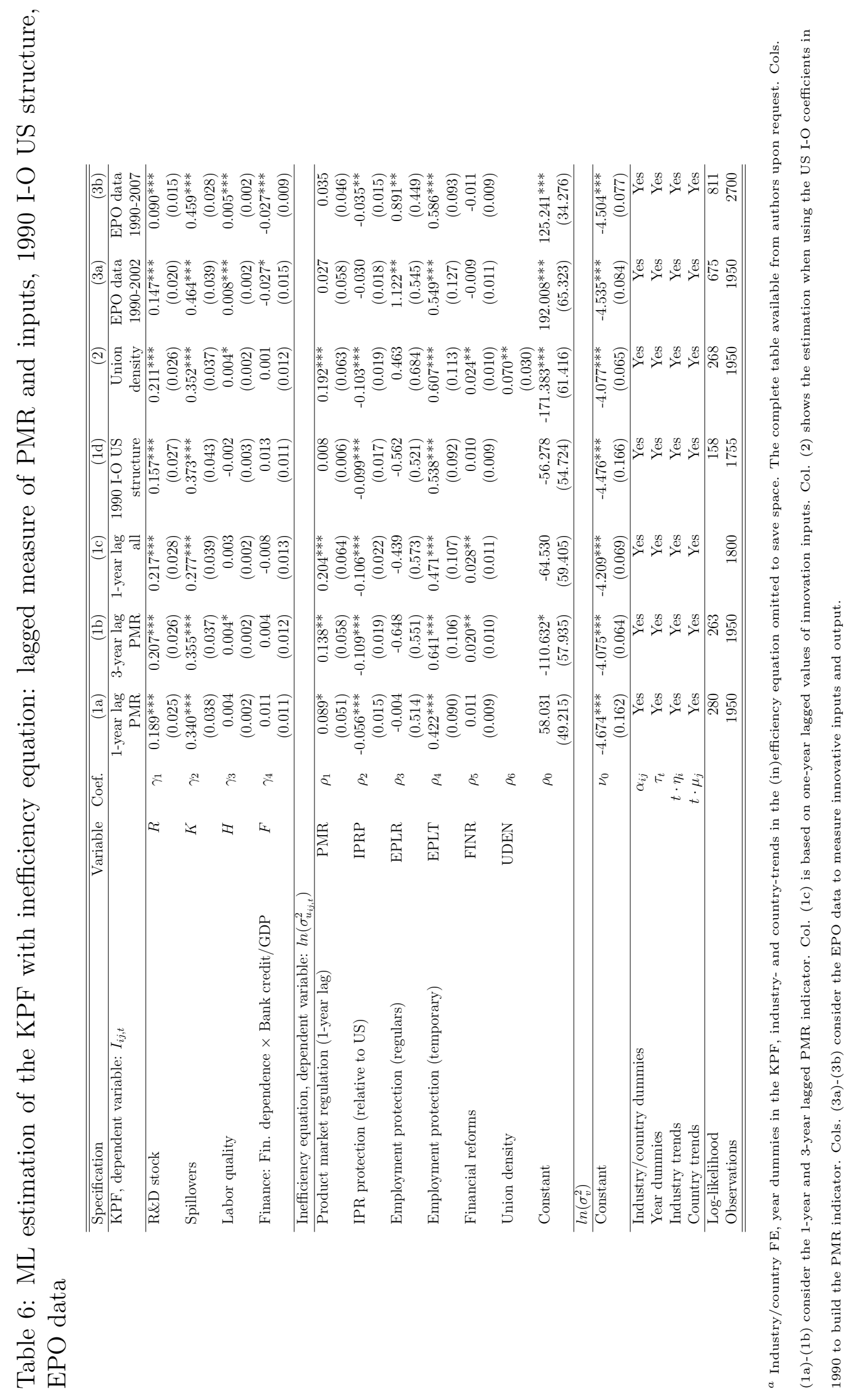




\section{Discussion}

This section discusses the econometric results and the associated policy implications. As a first step, we compute the mean efficiency scores for each industry/country pair from our benchmark specification (col. 4a, Table 2). In Figure 1, we report the country average scores evaluated at three reference years. ${ }^{18}$ It should be observed that, despite the econometric model includes a number of country-specific deterministic elements, well-defined nationwide patterns emerge in efficiency performance. In our sample, there are two outstanding economies: Japan and the US. The Netherlands and Sweden rapidly improved their performance during the 1990s, probably as a result of the increasing specialisation in (some) high-tech productions. Interestingly, Italy ranks relatively well in efficiency terms, albeit being a laggard either for innovative output or research effort. Table 7 details average efficiency scores by country and industry, revealing that disparities between the leading and following countries are larger in technologically advanced industries, such as office machinery, electrical equipment, communication equipment and other transport equipment.

Next, we calculate the marginal effect of upstream regulation with a view to raising the economic interpretation of the econometric results. In doing so, we track how the unit impact

\footnotetext{
${ }^{18}$ Efficiency scores are calculated for each country $j$ on an annual base as: $\sum_{i} T E_{i j, t} / I$, where $T E_{i j, t}=$ $\exp \left(-\widehat{u}_{i j, t}\right)$. Inefficiency scores are obtained through the conditional (to the overall residual) mean estimator, corrected for heteroskedasticity, developed by Jondrow et al. (1982):

$$
\widehat{u}_{i j, t}=E\left(u_{i j, t} \mid \epsilon_{i j, t}\right)=\frac{\sigma_{v} \sigma_{u_{i j, t}}}{\sigma_{i j, t}}\left[\frac{\phi\left(\frac{\epsilon_{i j, t} \lambda_{i j, t}}{\sigma}\right)}{1-\Phi\left(\frac{\epsilon_{i j, t} \lambda_{i j, t}}{\sigma_{i j, t}}\right)}-\left(\frac{\epsilon_{i j, t} \lambda_{i j, t}}{\sigma_{i j, t}}\right)\right] \text {, }
$$

where $\sigma_{i j, t}=\sqrt{\sigma_{v}^{2}+\sigma_{u_{i j, t}}^{2}}, \lambda_{i j, t}=\sigma_{u_{i j, t}} / \sigma_{v}$, and $\phi(\cdot)$ and $\Phi(\cdot)$ denote, respectively, the density function and the cumulative function of the standard normal distribution. Estimates of $\epsilon_{i j, t}$ are directly recoverable from eq. (3): $\widehat{\epsilon}_{i j, t}=I_{i j, t}-\widehat{\alpha}-\widehat{\theta} \ln Z_{i j, t}-\widehat{\alpha}_{i j}-\widehat{\tau}_{t}$. The employed empirical specification (Eq. 3 of the KPF is well-suited to separate out the time-invariant unobserved heterogeneity component, $\widehat{\alpha}_{i j}$, from time-variant inefficiency at the industry/country level, $\widehat{u}_{i j, t}$. Nonetheless, along with 'pure' heterogeneity, $\widehat{\alpha}_{i j}$ may also capture the time-invariant part of efficiency (as underlined by Pieri and Zaninotto (2013, pp. 411-2) among others), and it could be consequently used in the calculation of the efficiency scores. However, as Kumbhakar et al. 2014, pp. 325-6) point out, the method used to compute the efficiency scores is mainly a matter of parameters' interpretation decided by the researcher. Furthermore, rather encouragingly, the Pearson and Spearman rank correlation coefficients between $T E_{i j, t}=\exp \left(\widehat{u}_{i j, t}\right)$ and $\widehat{\alpha}_{i j^{-}} \widehat{u}_{i j, t}(0.57$ and 0.65$)$ indicate a wide similarity between these two 'ways' of computing the efficiency scores.
} 
Figure 1: Average technical efficiency by country, selected years

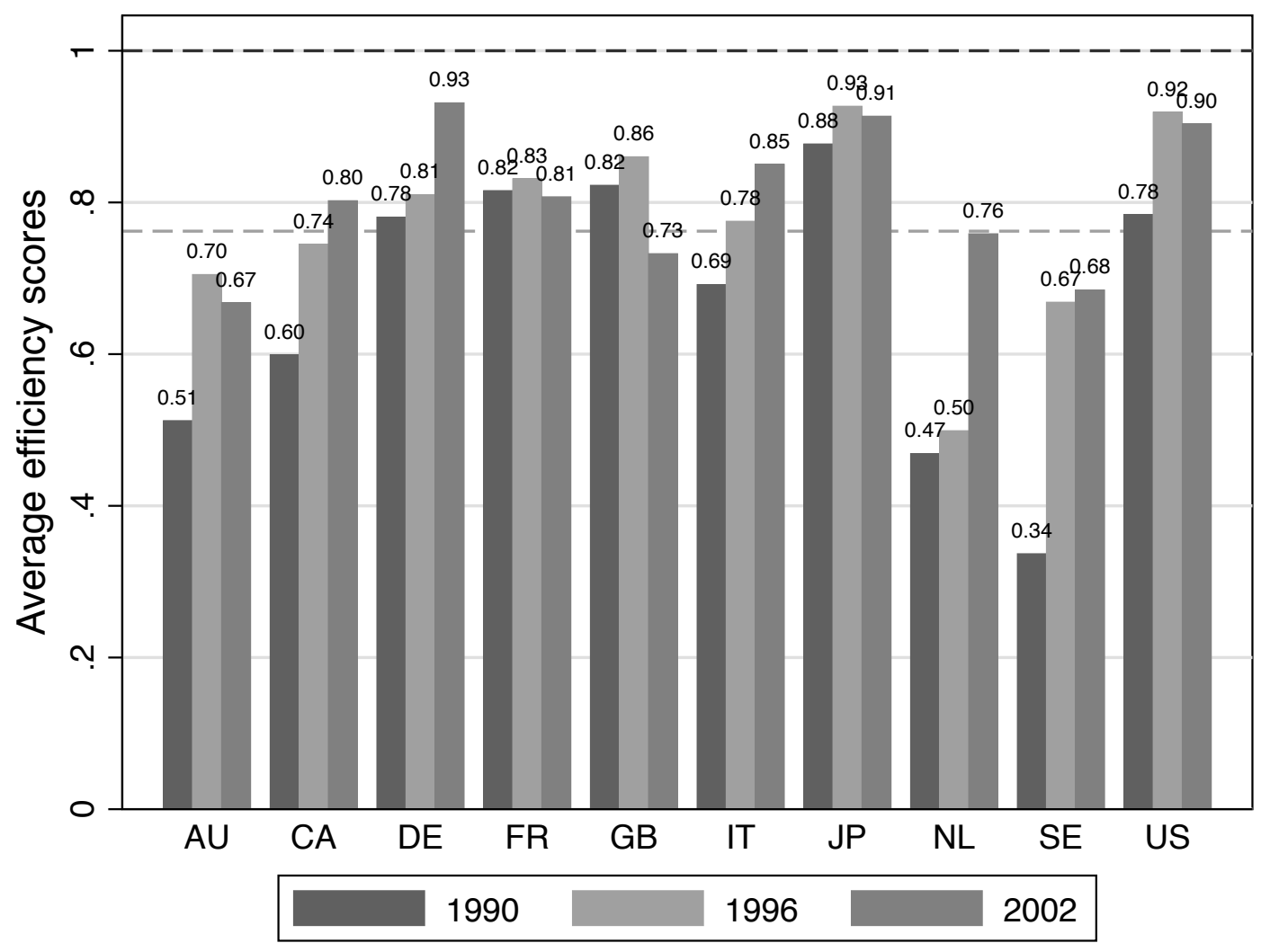

of PMR changes along its distribution in order to verify whether there are non-linearities in the effect of this variable. ${ }^{19}$

The mean partial effect amounts to 0.022. It implies that an unit decrease in regulation is associated with a $2.2 \%$ increase (reduction) in R\&D efficiency (inefficiency) and, through this channel, in patenting. This value is comparable in size to the effect of PMR on the employment rate $(0.3-0.4 \%)$, investment $(1 \%)$, and convergence rates towards the productivity frontier (6-12\%) found in earlier studies. ${ }^{20}$ Intuitively, using the sample average value

\footnotetext{
${ }^{19}$ Following Liu and Myers (2009), marginal effects are defined as:

$$
\frac{\partial\left[E\left(u_{i j, t} \mid \ln Z_{i j, t}, P M R_{i j, t}, \mathbf{W}\right)\right]}{\partial P M R_{i j, t}} .
$$

${ }^{20}$ See respectively Fiori et al. (2012), Alesina et al. (2005), Bourlès et al. (2013).
} 
Table 7: Efficiency scores by country and industry: averages

\begin{tabular}{lccccccccccc}
\hline Industry $\backslash$ Country & AU & CA & DE & FR & GB & IT & JP & NL & SE & US & TOTAL \\
\hline Food, beverage and tobacco & 0.59 & 0.73 & 0.79 & 0.69 & 0.64 & 0.71 & 0.87 & 0.53 & 0.55 & 0.84 & 0.69 \\
Chemicals & 0.71 & 0.86 & 0.94 & 0.92 & 0.91 & 0.88 & 0.96 & 0.79 & 0.81 & 0.95 & 0.87 \\
Pharmaceuticals & 0.58 & 0.65 & 0.86 & 0.76 & 0.73 & 0.74 & 0.88 & 0.60 & 0.56 & 0.81 & 0.72 \\
Rubber and plastics & 0.71 & 0.86 & 0.92 & 0.90 & 0.90 & 0.78 & 0.95 & 0.74 & 0.69 & 0.93 & 0.84 \\
Other non-metallic minerals & 0.73 & 0.82 & 0.89 & 0.88 & 0.85 & 0.82 & 0.94 & 0.72 & 0.68 & 0.92 & 0.82 \\
Basic metals & 0.65 & 0.82 & 0.88 & 0.82 & 0.77 & 0.66 & 0.92 & 0.58 & 0.63 & 0.90 & 0.76 \\
Fabricated metal products & 0.61 & 0.78 & 0.88 & 0.82 & 0.83 & 0.74 & 0.93 & 0.55 & 0.69 & 0.91 & 0.77 \\
Machinery & 0.86 & 0.93 & 0.96 & 0.95 & 0.95 & 0.93 & 0.98 & 0.86 & 0.85 & 0.97 & 0.92 \\
Office machinery & 0.38 & 0.53 & 0.66 & 0.67 & 0.65 & 0.63 & 0.86 & 0.36 & 0.41 & 0.76 & 0.59 \\
Electrical equipment and apparatus & 0.49 & 0.76 & 0.76 & 0.83 & 0.79 & 0.70 & 0.84 & 0.29 & 0.64 & 0.87 & 0.70 \\
Communication equipment & 0.52 & 0.54 & 0.67 & 0.79 & 0.81 & 0.69 & 0.89 & 0.38 & 0.47 & 0.82 & 0.66 \\
Medical and scientific instruments & 0.74 & 0.83 & 0.91 & 0.90 & 0.90 & 0.87 & 0.95 & 0.54 & 0.74 & 0.92 & 0.83 \\
Motor vehicles & 0.71 & 0.66 & 0.77 & 0.85 & 0.81 & 0.72 & 0.91 & 0.56 & 0.63 & 0.88 & 0.75 \\
Other transport equipment & 0.64 & 0.56 & 0.78 & 0.77 & 0.74 & 0.59 & 0.84 & 0.41 & 0.56 & 0.87 & 0.68 \\
Other manufacturing & 0.73 & 0.85 & 0.91 & 0.87 & 0.88 & 0.82 & 0.94 & 0.65 & 0.69 & 0.92 & 0.83 \\
TOTAL & 0.64 & 0.74 & 0.84 & 0.83 & 0.81 & 0.75 & 0.91 & 0.57 & 0.64 & 0.88 & 0.76 \\
\hline
\end{tabular}

as benchmark, our evidence indicates that if upstream regulation halved (from 9 to 4.5\%), R\&D efficiency would increase by $10 \%$, and the number of patents would approximately rise from 3 to 3.3 per thousand employee.

Figure 2 plots the partial effect of upstream regulation on $R \& D$ inefficiency observed on each industry/country pair against the PMR distribution, as well as the corresponding linear interpolations, at the beginning and at the end of the sample period (denoted in grey and black, respectively). The graph also reports the average marginal impact at the country level (marked by red diamonds and blue circles). Figure 2 illustrates four main points. First, the effect of regulation on inefficiency is positive along the entire distribution of PMR. Second, the highest unit impact is not found for the most regulated countries (Italy, Japan and Germany), but for the economies more prone to market competition such as the Netherlands (negative slopes). Third, the unit impact of regulation decreased during the 1990s as a result of the deregulation wave (closer interpolation line to the $\mathrm{x}$-axis in 2002). Forth, in terms of $\mathrm{R} \& \mathrm{D}$ efficiency, the cost of regulation is higher after liberalization (steeper slope in 2002). Overall, our findings indicate that product market reform programmes are unlikely to produce sizeable effects on $R \& D$ efficiency at the earlier stages of deregulation, similarly to what found by Alesina et al. (2005) on investment. Figure 2 shows that the 
negative relationship between marginal impact and level of regulation strengthened during the 1990s as OECD economies started opening their product markets. The partial impact of PMR was largely heterogeneous among countries at the beginning of the 1990s, but in the subsequent decade it converged both in terms of levels and dispersion.

Our results indicate that for late reformers, although the unit benefits from deregulation are relatively modest, total gains may be substantial. For instance, if Italy reduced service regulation to the US levels (i.e. a ten points reduction), it could obtain a $22 \%$ increase in R\&D efficiency and patenting (total gains $=$ unit impact $\times$ change in regulation levels). This value largely exceeds the benefits that could be obtained from convergence towards to the US standards by a low regulated country such as Canada $(2.9 \%=2.2 \% \times 1.3)$.

Figure 2: Marginal effect of PMR on inefficiency

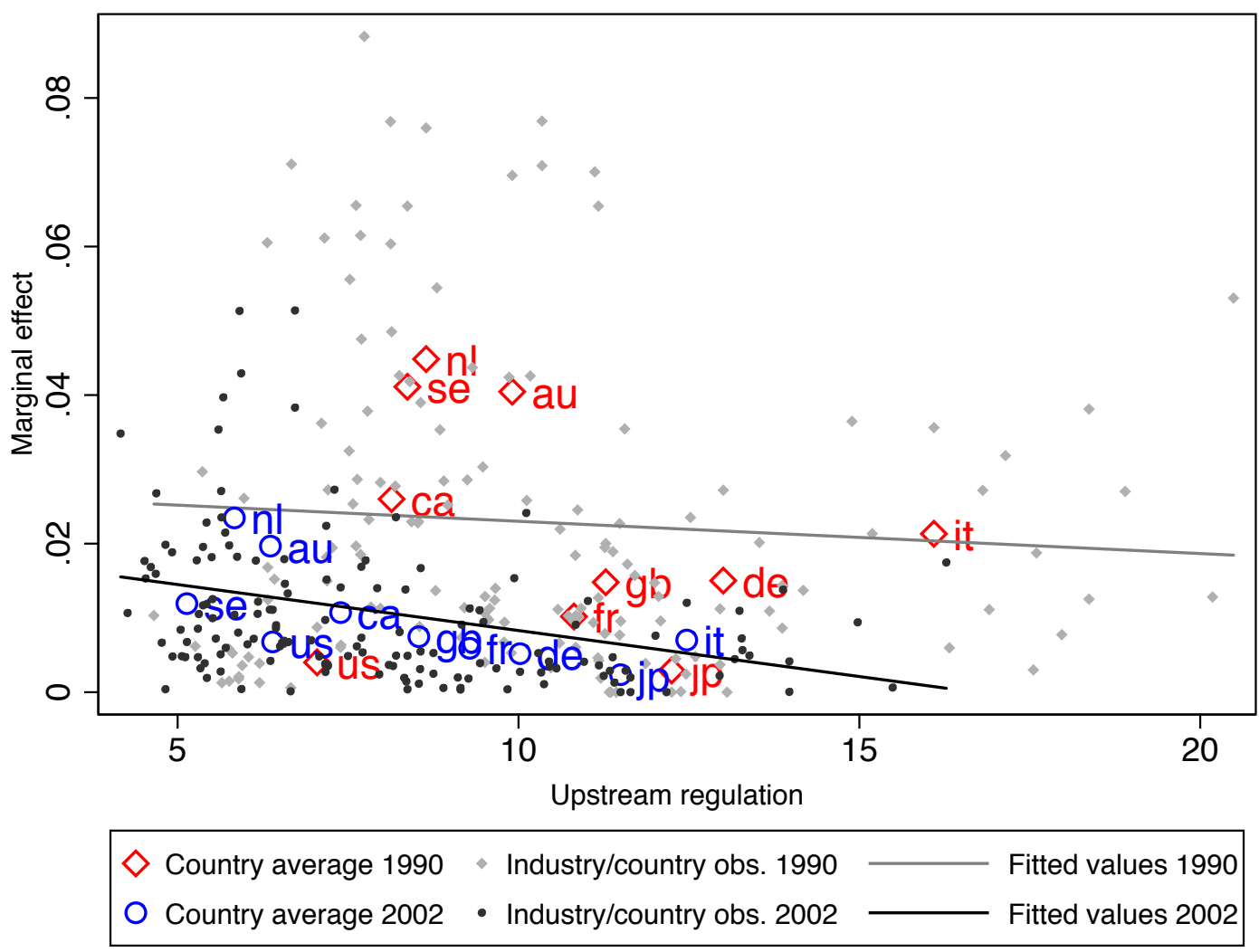




\section{Concluding remarks}

As R\&D-based endogenous growth theories influentially state, knowledge creation is one of the crucial forces to expand at a stable rate in the global economy. However, the ability to efficiently manage R\&D resources, and therefore to achieve better growth performances, cannot be taken for granted.

There is widespread evidence indicating that barriers to competition hamper the market entry and the arrival of new innovations. Thus far, less explored has been the issue of how the regulation in the upstream product markets reverberates on downstream innovation. This paper has filled this lack undertaking a stochastic frontier analysis on the knowledge production function of a large sample of OECD industries, investigating whether regulation in the service sector influences efficiency levels in innovation activities conducted by the manufacturing industries.

Our econometric analysis clearly shows that upstream PMR depresses R\&D efficiency downstream. This finding is robust to controlling for a large array of institutional factors such as IPR protection, employment protection legislation and financial regulation. In the post-estimation analysis, we have computed the marginal effect of PMR and verified whether its unit impact changes with the stringency of the regulatory setting. We have seen that the detrimental effect of this institutional factor is stronger in less regulated economies. The negative relationship between unit impact and level of regulation strengthened during the 1990s when product market reforms were launched by most OECD economies. These findings have important implications for policy-making as suggesting that significant improvements in R\&D efficiency, patenting, and more generally innovation outcomes, cannot be achieved in a relatively short-term horizon, or at the beginning of the deregulation programmes. Market liberalization takes time to produce widespread effects within the economy. In absolute terms, gains from deregulation are however more relevant for those countries starting from a more restrictive setting to competition. 


\section{References}

Abiad, A., Detragiache, E., Tressel, T., 2008 A new database of financial reform. MF Working Paper WP/08/266.

Acharya, R.C., Keller, W., 2009. Technology transfer through imports. Canadian Journal of Economics, 42, 1411-1448.

Aghion, P., Harris, Vickers, J. 1997. Competition and Growth with Step-by-Step Innovation; An Example. European Economic Review, 41, 771-782.

Aghion, P., Bloom, N., Blundell, R., Griffith, R., Howitt, P., 2005. Competition and innovation: An inverted-U relationship. Quarterly Journal of Economics, 120, 701-728.

Aghion, P., Blundell, R., Griffith, R., Howitt, P., Prantl, S., 2009. The effects of entry on incumbent innovation and productivity. Review of Economics and Statistics, 91, 20-32.

Aghion, P., Akcigit, U., Howitt, P., 2013a. What do we learn from Schumpeterian growth theory?. NBER working paper No. 18824.

Aghion, P., Howitt, P., Prantl, S., 2013b. Patent rights, product market reforms, and innovation. NBER working paper No. 18854.

Aigner, D. Lovell, K., Schmidt, P. 1977. Formulation and estimation of stochastic frontier production function models. Journal of Econometrics, 6, 21-37

Alesina, A., Ardagna, S., Nicoletti, G., Schiantarelli, F., 2005. Regulation and investment Journal of the European Economic Association, 4, 791-825.

Amable, B., Demmou, L., Ledezma, I., 2009. Product market regulation, innovation and distance to frontier. Industrial and Corporate Change, 19, 117-159.

Ang, J. B., 2011. Financial development, liberalization and technological deepening? European Economic Review, 55, 688-701. 
Ang, J. B., Madsen, J. B., 2011. Can second-generation endogenous growth models explain the productivity trends and knowledge production in the Asian miracle economies? Review of Economics and Statistics, 93, 1360-1373.

Arnold, J., Nicoletti, G., Scarpetta, S., 2011. Does Anti-Competitive Regulation Matter for Productivity? Evidence from European Firms. IZA Discussion Papers No. 5511.

Barbosa, N., Faria, A.P., 2011. Innovation across Europe: How important are institutional differences? Research Policy, 40, 1157-1169.

Barone G., Cingano F., 2011. Service regulation and growth: Evidence from OECD countries. Economic Journal, 121, 931-957.

Bassanini, A., Nunziata, L., Venn, S., 2009. Job protection legislation and productivity growth in OECD countries. Economic Policy, 24, 349-402.

Bassanini, A., Brunello, G., 2011. Barriers to entry, deregulation and workplace training: A theoretical model with evidence from Europe. European Economic Review, 55, 1152-1176.

Beck, T., Demirgü-Kunt, A., 2009. Financial institutions and markets across countries and over time: Data and analysis. World Bank Policy Research Working Paper No. 4943.

Blind, K., 2012. The influence of regulations on innovation: A quantitative assessment for OECD countries. Research Policy, 41, 391-400.

Boldrin, M., Levine, D.K., 2013 The case against patents. Journal of Economic Perspectives, $27,3-22$.

Bottazzi, L., Peri, G. 2007. The international dynamics of R\&D and innovation in the short and long run Economic Journal 117, 486-511.

Bourlès R., Cette G., Lopez J., Mairesse J., Nicoletti G., 2013. Do Product Market Regulations in upstream sectors curb productivity growth? Panel data evidence for OECD Countries. Review of Economics and Statistics, 95,1750-1768. 
Buccirossi, P., Ciari, L., Duso, T., Spagnolo, G., Vitale, C., 2013. Competition policy and productivity growth: An empirical assessment. Review of Economics and Statistics, 95, 1324-1336.

Ciccone, A., Papaioannou,E., 2010. Estimating Cross-Industry Cross-Country Models Using Benchmark Industry Characteristics Working Papers 504, Barcelona Graduate School of Economics.

Caudill, S., Ford, J. 1993. Biases in frontier estimation due to heteroskedasticity. Economics Letters, 41, 17-20

Conway, P., Nicoletti, G. 2006. Product market regulation in the non-manufacturing sectors of OECD countries: Measurement and highlights. OECD Economics Department Working Papers 530 .

Conway, P., De Rosa, D., Nicoletti,G., Steiner, F. 2006. Regulation, competition and productivity convergence. OECD Economic Studies vol. 2, 9.

Correa, J.A., Ornaghi, C., 2014. Competition and Innovation: Evidence from U.S. Patent and Productivity Data. Journal of Industrial Economics,62, 258-285

Cullmann, A., Schmidt-Ehmcke, J., Zloczysti, P. 2012. R\&D efficiency and barriers to entry: A two stage semi-parametric DEA approach. Oxford Economic Papers, 64, 176-196.

Fiori, G., Nicoletti G., Scarpetta, S., Schiantarelli, F. 2012. Employment effects of product and labour market reforms: Are there synergies? Economic Journal, 122, F79-F104.

Fu, X., Yang, Q. G., 2009. Exploring the cross-country gap in patenting: A stochastic frontier approach. Research Policy, 38, 1203-1213.

Franco, C., Montresor, S., Vittucci Marzetti, G. 2011. On indirect trade-related R\&D spillovers: The 'Average Propagation Length' of foreign R\&D. Structural Change and Economic Dynamics, 22, 227-237. 
Ginarte, J.C., Park, W.G. 1997. Determinants of patents rights: A cross-national study. Research Policy, 26, 283-301.

Greene, W. H. (2005) Reconsidering heterogeneity in panel data estimators of the stochastic frontier model. Journal of Econometrics, 126, 269-303.

Greene, W. H. (2008) The econometric approach to efficiency analysis. In H. O. Fried, C. A. K. Lovell, S. S. Schmidt (Eds.), The measurement of productive efficiency and productivity change, Chap. 2 (pp. 92-250). Oxford: Oxford University Press.

Griffith, R. Harrison, R.Macartney, G. 2007. Product Market reforms, labour market institutions and unemployment. Economic Journal, 117, C142-C166.

Griffith R., Harrison, R., Simpson., H., 2010. Product market reform and innovation in the EU. Scandinavian Journal of Economics, 112, 389-415.

Griffith, R., Macartney, G., 2014. Employment protection legislation, multinational firms and innovation. Review of Economics and Statistics, 96, 135-150.

Hall, B. H., Jaffe, A. B., Trajtenberg, M., 2001. The NBER citations data file: Lessons, insights and methodological tools. NBER Working papers 8498.

Henry, M., Kneller, R., Milner, C. 2009. Trade, technology transfer and national efficiency in developing countries. European Economic Review, 53, 237-254.

Inklaar, R., Timmer, M.P., van Ark, B. 2008. Market services productivity across Europe and the US. Economic Policy, 23, 139-194.

Jondrow, J., Lovell, C. A. K., Materov, S.,Schmidt, P. (1982) On the estimation of technical efficiency in the stochastic frontier production function model. Journal of Econometrics, $19,233238$.

Kneller, R., Stevens, P., 2006. Frontier technology and absorptive capacity: Evidence from OECD manufacturing industries. Oxford Bulletin of Economics and Statistics 68, 1-21. 
Kodde, D., Palm, F., 1986. Wald criteria for jointly testing equality and inequality restrictions. Econometrica, 54, 1243-1248.

Kumbhakar, S., Lovell, C. 2000. Stochastic Frontier Analysis. Cambridge University Press, Cambridge.

Kumbhakar, S., Lien, G., Hardaker, B. J. 2014. Technical efficiency in competing panel data models: a study of Norwegian grain farming. Journal of Productivity Analysis, 41, 321-337.

Liu, Y., Myers, R., 2009. Model selection in stochastic frontier analysis with an application to maize production in Kenya. Journal of Productivity Analysis, 31, 33-46.

Lopez, J., 2010. Essais sur la Rglementation du March des Biens, les Technologies de l'Information et de la Communication, la Recherche et Dveloppement et la Productivit PhD Dissertation, Ecoles des Hautes Etudes en Sciences Sociales, GREQAM D?AixMarseille.

Martin, J. and Scarpetta, S. 2012. Setting It Right: Employment Protection, Labour Reallocation and Productivity. De Economist, 160, 89-116.

Maskus, K. E., Neumann, R., Seidel, T., 2012. How national and international financial development affect industrial R\&D. European Economic Review, 56, 72-83.

Mason, G., O’Leary, B., Vecchi, M., 2012. Certified and uncertified skills and productivity growth performance: Cross-country evidence at industry level. Labour Economics, 19, 351-360.

Meeusen, W., van den Broeck, J., 1977. Efficiency estimation for Cobb-Douglas production functions with composed error. International Economic Review, 18, 435-444

Menezes-Filho, N., Van Reenen, J., 2003. Unions and innovation: A survey of the theory 
and empirical evidence. International Handbook of Trade Unions, pp. 293-334. Edward Elgar Publishing Ltd.

Nelson, R. R., 2008. What enables rapid economic progress: What are the needed institutions. Research Policy, 37, 1-11.

Nicoletti, G., Scarpetta, S., 2003. Unions and innovation: A survey of the theory and empirical evidence. Regulation, productivity and growth: OECD evidence. Economic Policy, 18, 9-72.

Pieri, F., Zaninotto, E., 2013. Vertical integration and efficiency: an application to the Italian machine tool industry. Small Business Economics, 40, 397-16.

Rajan, R.G., Zingales, L., 1998. Financial dependence and growth. American Economic Review, 88, 559-586.

Samaniego, R.M., 2013. Knowledge spillovers and intellectual property rights. International Journal of Industrial Organization, 31, 50-63.

Sanyal, P., Ghosh, S., 2013. Product Market Competition and Upstream Innovation: Theory and Evidence from the US Electricity Market Restructuring. Review of Economics and Statistics,95,237-254

Schmidt, P., 2011. One-step and two-step estimation in SFA models Journal of Productivity Analysis, 36, 201-203.

Venn, D. 2009. Legislation, collective bargaining and enforcement: Updating the OECD employment protection indicators Social, Employment and Migration Working Paper no. 89, OECD, Paris.

Venturini, F., 2012. Looking into the black-box of Schumpeterian theory: An assessment of R\&D races. European Economic Review, 56, 1530-1545. 
Venturini, F., 2014. The modern drivers of productivity. Research Policy, forthcoming, DOI:10.1016/j.respol.2014.10.011

Von Furstenberg G.M, Von Kalckreut, U., 2006. Dependence on external finance: An inherent industry characteristic?. Open Economies Review, 17, 541-559.

Wang, H-J., Schmidt, P., 2002. One-Step and two-step estimation of the effects of exogenous variables on technical efficiency levels. Journal of Productivity Analysis, 18, 129-144.

Wang, E. C., 2007. R\&D efficiency and economic performance: A cross-country analysis using the stochastic frontier approach. Journal of Policy Modeling, 39, 345-360. 